Archives of Anesthesiology

Volume 1, Issue 1, 2018, PP: 27-27

\title{
Writing Quality Manuscripts
}

\section{Bhavna Gupta*}

Senior Resident, department of Anesthesia and ICU, MAMC and LokNayak Hospital, India. bhavna.kakkar@gmail.com

*Corressponding Author: Bhavna Gupta, Senior Resident, department of Anesthesia and ICU, MAMC and LokNayak Hospital, India.

First of all I congratulate the entire team of Archives of Anesthesiology for introducing Inaugural issue in the month of May 2018. We assure that the entire editorial board team will make all efforts to keep high standards of the articles being published in the journal at the same time ensuring the double blind peer review mechanism. The journal contains section for editorials, original articles, review articles, case reports and letter to editor. The journal also ensures an open access to give special opportunity to anesthesiologists to present their research work to reach the masses.

While we assure our commitment to make the Archives of Anesthesiology, vibrant and successful, at the same time, we need constant source of encouragement and support by contribution of your research work and critical evaluation of contents. The authors should carefully review the 'instruction for authors' available at the online site and should carefully abide by the same to allow quality work to flow. The article should be structured in a logical way and written in a coherent style. Correct use of grammar, quality of images, quoting references at appropriate places are important to the quality of paper and impression it gives the reviewers.

While submitting original articles, authors should ensure the clinical registry of the studies before the trial was begun. Informed consent, protection of patient's identity should be ensured while submitting the manuscripts. Also it is the author's duty to ensure that statistical analysis is appropriately done and described in the manuscript. Authors should also ensure that the references are correct and appropriately cited in the text. It is also important to ensure the novelty of the data being presented to the journal. Plagiarism or fabrication of data leads to loss of credibility and creates a poor image. Authors should make sure to take permission from the copyright holder in case published images or figures or tables are re used.

In case the study has a source of financial support, the same should be declared. And also in case, the authors have conflict of interest, the same should also be mentioned. Authors should not submit a single manuscript to multiple journals at the same time. Sometimes, the article may get rejected before getting evaluated by the reviewers, owing to incorrect methodology, repetition of already published literature or lack of novelty. Authors should take the rejection in a healthy way and should not let down the anger as letter to editor. This can create a sense of negative impact of the author concerned. It is best to revise the manuscript according to the changes stated by the reviewers before resubmitting to the other journal. Perseverance and hard work are the key to success, and the authors should keep trying and write their valuable research articles for possible publication. Getting an article published in a reputed journal gives a feeling of accomplishment and is associated with advancement in knowledge and overall career development of an individual. I request all the readers to contribute to the success of our journal by sending your valuable research articles, case reports and letter to editor.

Citation: Bhavna Gupta. Writing Quality Manuscripts. Archives of Anesthesiology. 2018; 1(1): 27-27.

Copyright: (C) 2018 Bhavna Gupta. This is an open access article distributed under the Creative Commons Attribution License, which permits unrestricted use, distribution, and reproduction in any medium, provided the original work is properly cited. 